2008

\title{
Mycobacteriosis-Associated Mortality in Wild Striped Bass (Morone Saxatilis) from Chesapeake Bay, USA
}

D. T. Gauthier

Old Dominion University, dgauthie@odu.edu

R.J. Latour

D. M. Heisey

C. F. Bonzek

J. Gartland

See next page for additional authors

Follow this and additional works at: https://digitalcommons.odu.edu/biology_fac_pubs

Part of the Aquaculture and Fisheries Commons, Ecology and Evolutionary Biology Commons, and the Environmental Sciences Commons

\section{Repository Citation}

Gauthier, D. T.; Latour, R. J.; Heisey, D. M.; Bonzek, C. F.; Gartland, J.; Burge, E. J.; and Vogelbein, W. K., "Mycobacteriosis-Associated Mortality in Wild Striped Bass (Morone Saxatilis) from Chesapeake Bay, USA" (2008). Biological Sciences Faculty Publications. 172. https://digitalcommons.odu.edu/biology_fac_pubs/172

\section{Original Publication Citation}

Gauthier, D. T., Latour, R. J., Heisey, D. M., Bonzek, C. F., Gartland, J., Burge, E. J., \& Vogelbein, W. K. (2008). Mycobacteriosisassociated mortality in wild striped bass (Morone saxatilis) from Chesapeake Bay, USA. Ecological Applications, 18(7), $1718-1727$. doi:10.1890/07-2083.1 
Authors

D. T. Gauthier, R. J. Latour, D. M. Heisey, C. F. Bonzek, J. Gartland, E. J. Burge, and W. K. Vogelbein 


\title{
MYCOBACTERIOSIS-ASSOCIATED MORTALITY IN WILD STRIPED BASS (MORONE SAXATILIS) FROM CHESAPEAKE BAY, USA
}

\author{
D. T. Gauthier, ${ }^{1,5}$ R. J. Latour, ${ }^{2}$ D. M. Heisey ${ }^{3}$ C. F. Bonzek, ${ }^{2}$ J. Gartland,${ }^{2}$ E. J. Burge,${ }^{4}$ \\ AND W. K. VOGELBeIN ${ }^{1}$ \\ ${ }^{1}$ Department of Environmental and Aquatic Animal Health, Virginia Institute of Marine Science, \\ Gloucester Point, Virginia 23062 USA \\ ${ }^{2}$ Department of Fisheries Science, Virginia Institute of Marine Science, Gloucester Point, Virginia 23062 USA \\ ${ }^{3}$ U.S. Geological Survey, National Wildlife Center, Madison, Wisconsin 53711 USA \\ ${ }^{4}$ Department of Marine Science, Coastal Carolina University, Conway, South Carolina 29528 USA
}

\begin{abstract}
The striped bass (Morone saxatilis) is an economically and ecologically important finfish species along the Atlantic seaboard of the United States. Recent stock assessments in Chesapeake Bay (USA) indicate that non-fishing mortality in striped bass has increased since 1999, concomitant with very high $(>50 \%)$ prevalence of visceral and dermal disease caused by Mycobacterium spp. Current fishery assessment models do not differentiate between disease and other components of non-fishing mortality (e.g., senescence, predation); therefore, disease impact on the striped bass population has not been established. Specific measurement of mortality associated with mycobacteriosis in wild striped bass is complicated because the disease is chronic and mortality is cryptic. Epidemiological models have been developed to estimate disease-associated mortality from cross-sectional prevalence data and have recently been generalized to represent disease processes more realistically. Here, we used this generalized approach to demonstrate disease-associated mortality in striped bass from Chesapeake Bay. To our knowledge this is the first demonstration of cryptic mortality associated with a chronic infectious disease in a wild finfish. This finding has direct implications for management and stock assessment of striped bass, as it demonstrates population-level negative impacts of a chronic disease. Additionally, this research provides a framework by which disease-associated mortality may be specifically addressed within fisheries models for resource management.
\end{abstract} bass.

Key words: disease-associated mortality; force-of-infection; Morone saxatilis; mycobacteriosis; striped

\section{INTRODUCTION}

The anadromous striped bass, Morone saxatilis, is one of four dominant piscivores in the Chesapeake Bay (USA) and fills a critical ecological niche in estuarine food webs (Hartman and Brandt 1995, Latour et al. 2008). Striped bass are also of high economic importance, forming the basis for large recreational and commercial fisheries within Chesapeake Bay (Kirkley et al. 2000). Disease outbreaks have been reported in Chesapeake Bay striped bass since the late 1980s. Mortality in fish from Maryland waters of the Bay in 1988 was associated with Streptococcus spp. (Baya et al. 1990), and visceral and dermal lesions observed in 1994 were attributed to Edwardsiella spp. (Baya et al. 1997). Beginning in 1997, striped bass exhibiting poor body condition and ulcerative skin lesions were observed in Virginia and Maryland waters of Chesapeake Bay.

Manuscript received 19 December 2007; revised 19 March 2008; accepted 26 March 2008. Corresponding Editor: K. B. Gido.

${ }^{5}$ Present address: Department of Biological Sciences, 106E Mills Godwin Building, Old Dominion University, Norfolk, Virginia 23529 USA. E-mail: dgauthie@odu.edu
Histopathology revealed granulomatous inflammation associated with acid-fast bacteria, consistent with infection by Mycobacterium spp. (Vogelbein et al. 1999). Subsequent surveys have demonstrated high $(>50 \%)$ prevalence of visceral and dermal mycobacteriosis in striped bass from Chesapeake Bay (Vogelbein et al. 1999, Cardinal 2001, Overton et al. 2003). Coincident with reports of high disease prevalence, recent fishery stock assessments have demonstrated an increase in natural, non-fishing mortality among striped bass in Maryland waters since 1999 (Jiang et al. 2007). These observations suggest that mycobacteriosis may be responsible for increased natural mortality of striped bass. As with most fishery assessment models, however, that of Jiang et al. (2007) does not differentiate between disease and other components of non-fishing mortality, such as predation and senescence. Therefore, the relationship between disease and increased natural mortality has not yet been established.

Mycobacteriosis is a subacute to chronic disease common in wild and captive fishes worldwide. Mortality resulting from mycobacteriosis is not generally reported in wild finfish populations, although high mortality is commonly observed in aquaculture (Nigrelli and Vogel 
1963, Hedrick et al. 1987, Bruno et al. 1998). Mycobacterium marinum, M. fortuitum, and $M$. chelonae are the most frequently cultured isolates from diseased fishes, although several other species have been reported (Lansdell et al. 1993, Tortoli et al. 1996, Herbst et al. 2001, Whipps et al. 2003, Rhodes et al. 2004). In most cases, disease is visceral, with spleen, liver, and kidney being the primary target organs. Granulomatous inflammation, often with extensive tissue destruction, is characteristic, although more poorly organized inflammatory responses are observed, typically in association with high bacillary loads (Kent et al. 2004). External clinical signs include scale loss, skin ulceration, emaciation, exophthalmia, pigmentation changes, and spinal defects (Nigrelli and Vogel 1963, Snieszko 1978, Wolke and Stroud 1978, Bruno et al. 1998). Mycobacteriosis has previously been described in wild and cultured striped bass from the U.S. Pacific Coast, with prevalence values as high as $68 \%$ and $80 \%$, respectively (Sakanari et al. 1983, Hedrick et al. 1987).

Characterization and identification of Mycobacterium spp. associated with the epizootic of mycobacteriosis in Chesapeake Bay striped bass are ongoing. A number of isolates have been cultured, including the fish pathogen $M$. marinum, the newly described species $M$. shottsii and M. pseudoshottsii, and species typically considered to be saprophytes (e.g., M. gordonae; Rhodes et al. 2001, 2003, 2004). Other isolates do not exactly match known phenotypic profiles, and potentially represent additional new species (Rhodes et al. 2004). Mycobacterium shottsii and $M$. pseudoshottsii are the isolates most commonly recovered from diseased striped bass, and co-infections with multiple mycobacterial species occur (Rhodes et al. 2004). Both M. shottsii and M. pseudoshottsii are closely related to $M$. marinum and $M$. ulcerans, important pathogens of fishes and humans, respectively. IS2404, an insertion sequence associated with mycolactone, a plasmid-encoded polyketide toxin, has been detected in M. pseudoshottsii, and production of variant mycolactones has been demonstrated by this species, as well as other related fish-pathogenic mycobacteria (Rhodes et al. 2005, Ranger et al. 2006, Yip et al. 2007).

Observation of mortality among wild finfishes is typically limited to acute kill events of schooling species (e.g., Patterson 1996, Whittington et al. 1997, Blazer et al. 2002). Due to the chronic nature of mycobacteriosis in striped bass, however, mortality is cryptic, and has not been measurable previously. Several modeling approaches have been developed to estimate diseaseassociated mortality from cross-sectional prevalence data (Cohen 1973, Caley and Hone 2002), and have recently been generalized to allow use of complex agevarying hazards that more realistically represent disease processes (Heisey et al. 2006). In this study, we apply the approach of Heisey et al. (2006) to a comprehensive three-year survey of mycobacteriosis in Chesapeake Bay striped bass. This work was conducted using the Chesapeake Bay Multispecies Monitoring and Assess-

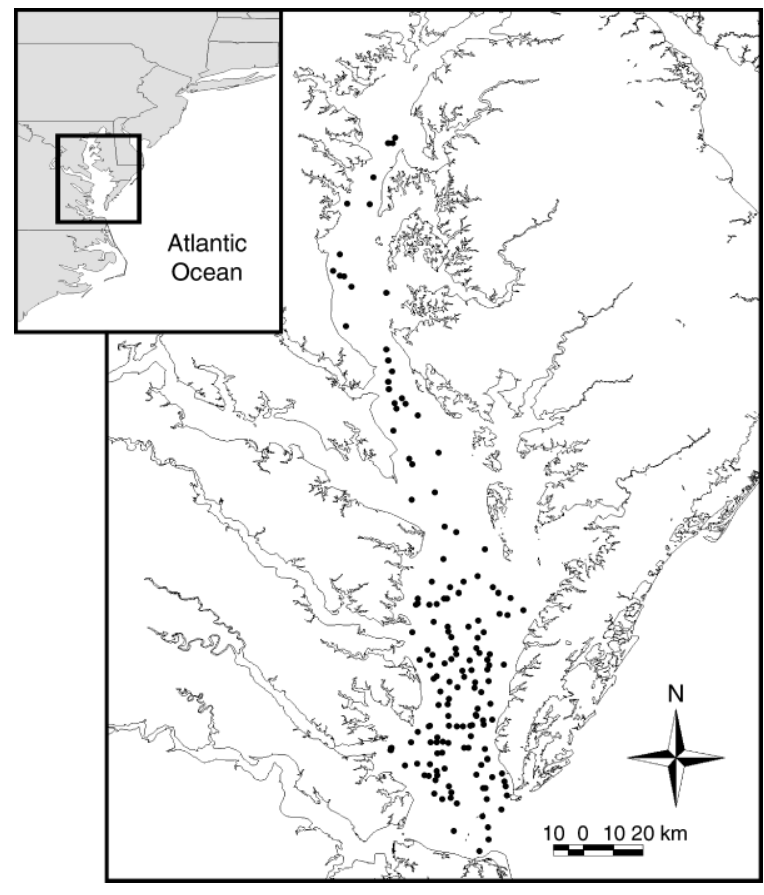

FIG. 1. A representative distribution of sampling locations (black dots) within Chesapeake Bay (USA) for the Chesapeake Bay Multispecies Monitoring and Assessment Program (ChesMMAP) survey from 2003 to 2005. A comparable spatial coverage was achieved during each cruise.

ment Program (ChesMMAP), which is a fisheriesindependent survey in support of ecosystem-based approaches to fisheries management. We present apparent prevalence data with respect to age, sex, and cruise (season), and examine age dependency of force-ofinfection, influence of covariates on force-of-infection, and existence of disease-associated mortality.

\section{Materials And Methods \\ Field collections}

Striped bass were collected by the ChesMMAP survey in the main stem of Chesapeake Bay. During 2003-2005, a total of 15 cruises were conducted (annually during March, May, July, September, and November) and 80 90 sites were sampled per cruise (Fig. 1). Sampling locations were chosen according to a stratified random design, with strata based on water depth (3-9 m, 9-15 m, and $>15 \mathrm{~m}$ ) within five latitudinal 30-minute regions of the bay. The number of locations sampled in each regional stratum was randomly selected in proportion to its area. At each sampling location, a $13.7 \mathrm{~m}$, four-seam balloon otter trawl $(15.2 \mathrm{~cm}$ stretch mesh in the wings and body and $7.6 \mathrm{~cm}$ stretch mesh in the cod end) was towed for $20 \mathrm{~min}$ at $\sim 6.5 \mathrm{~km} / \mathrm{h}$ with the current. If distinct size classes (based on fork length) of striped bass were evident in the catch, length measurements were coded according to a coarse size categorization (e.g., small, medium, large). A random subsample of each size 
class (if multiple classes were present) was further processed for visual sex determination, otolith-based ageing, and histological detection of splenic mycobacteriosis.

\section{Laboratory procedures}

A transverse section of the right sagittal otolith was used to determine fish age following the methods of Secor et al. (1995). Annuli were counted by viewing the slide under a dissecting microscope using transmitted light $(25 \times$ magnification). Three readers aged all specimens once and a randomly selected subsample of 200 specimens a second time. Year class ages were assigned based on the conventional 1 January birth date.

Spleens were fixed in Z-fix (Anatech, Battle Creek, Michigan, USA) for at least 72 hours, then divided transversely into six approximately equal portions, while removing an additional 1-2 $\mathrm{mm}$ section between portions to avoid examination of contiguous sections. Portions were then processed for routine paraffin histology (Prophet et al. 1992). If all six portions for an individual spleen would not fit in one cassette, portions were randomized and distributed to multiple cassettes. Sections were cut at $5 \mu \mathrm{m}$ and stained with hematoxylin and eosin (HE). One section of up to six spleen portions and a $50-\mu \mathrm{m}$ step section were included on each slide. Tissue sections were examined on an Olympus AX-70 light microscope (Olympus, Center Valley, Pennsylvania, USA) for the presence of granulomas. A granuloma was defined as any lesion containing epithelioid macrophages (Cotran et al. 1999). Granulomas containing helminth parasites (typically metacercariae of digenean trematodes) were not counted. HE-stained sections were examined for granulomas until (1) 12 sections (six sections + six $50-\mu \mathrm{m}$ step sections) per fish were determined to be negative, or (2) granulomas were found.

\section{Statistical analyses}

Force-of-infection.- Various measures exist for establishing the occurrence of disease in an animal population. One such measure, cumulative incidence, is useful in that it allows calculation of the force-of-infection rate constant $\lambda$, according to the formula $\pi(t)=1-e^{(-\lambda t)}$, where $\pi(t)$ is cumulative incidence, or proportion of individuals that have become positive within the cohort, at time $t$. Measurement of cumulative incidence requires constant monitoring of a cohort over time (i.e., longitudinal monitoring), so that diseased individuals that die before time $t$ are still counted within the diseasepositive proportion. Thus cumulative incidence is not influenced by population age structure or diseaseassociated mortality, and may be thought of roughly as the "true" measure of disease occurrence in a study group. The longitudinal monitoring requirement, however, is seldom possible in studies of wild animals, especially finfishes.
Due to this logistical constraint, apparent prevalence, or the proportion of individuals in a sample that test positive for a disease of interest, is a more commonly used measure of disease in wild animal populations. Apparent prevalence is conveniently measured in a cross-sectional (i.e., single point-in-time) study design, but may be strongly influenced by population age structure and potentially by disease-associated mortality. Assuming that animals test negative for disease at birth, time of exposure to disease agents and risk factors increases with age. Thus the apparent prevalence is directly related to the age structure of the population. Disease-associated mortality preferentially removes diseased individuals from the study population, thus biasing cross-sectional samples toward negative individuals. Many studies estimating incidence from ageprevalence data avoid this complication, known as left truncation, by assuming the disease in question to be benign. Various models have, however, been designed for human (Podgor and Leske 1986, Keiding 1991) and wildlife (Cohen 1973, Woolhouse and Chandiwana 1992, Caley and Hone 2002) epidemiology to estimate force-of-infection from age-prevalence data while taking into account disease-associated mortality. To date, these models have been able to accommodate only ageinvariant or coarsely defined age-varying force-ofinfection hazards. A piecewise approximation method has recently been developed, however, which allows incorporation of disease-associated mortality into apparent prevalence-based models, including complex agevarying infection hazards functions (Heisey et al. 2006). Here, we apply this method to explore disease-associated mortality of striped bass in Chesapeake Bay, USA.

In this work, we refer to "force-of-infection," but the event we actually analyze is the onset of detectable disease (granulomatous inflammation). Indeed, in many epidemiological studies, some advanced disease state is used as a proxy for the infection event because the event itself is too subtle to be detected. Thus, in our case, the "force-of-infection" would be more accurately referred to as the "hazard of detectable disease." For the sake of readability and consistency with previous nomenclature, however, we use the former term.

The three-state irreversible disease model (Fig. 2) characterizes the probabilities of an individual being non-diseased, $N(t)$, diseased and alive, $P(t)$, or dead, $D(t)$ at age $t$ (Heisey et al. 2006). All animals are assumed to be born disease negative so that $N(0)=1$, $P(0)=0, D(0)=0$, and self cure is assumed not to occur. Transitions between states are controlled by three agespecific hazards functions: $\lambda(t)$ is the disease hazard, or the rate at which disease-negative animals become disease-positive; $\delta(t)$ is the rate at which disease-negative animals die; and $\delta(t)+\mu(t)$ is the disease-positive mortality hazard, which represents the additive disease-negative and disease-positive mortality rates. Note that the disease-associated hazard, $\mu(t)$ is assumed to be independent from background (disease-negative) mor- 
FIG. 2. Three-state irreversible disease model (see Heisey et al. 2006).

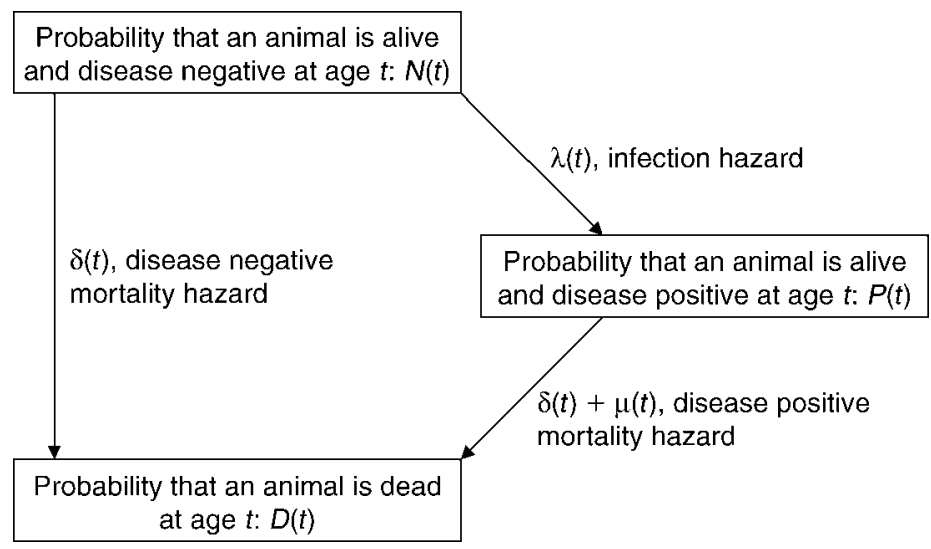

tality. Disease-associated hazard $\mu(t)$ thus potentially includes mortality directly resulting from disease, as well as indirect disease-related mortality mechanisms (e.g., higher susceptibility of diseased fish to capture or predation). Cause-specific mortality is not implied by $\mu(t)$.

From the three-state model, a system of differential equations can be constructed and solved for the state probabilities $N(t), P(t)$, and in turn $v(t)$, which is defined as the probability that an animal is disease positive conditional on being alive at age $t$; i.e., $\operatorname{Pr}(P=1 \mid t)=$ $v(t)$. If $\lambda(t)$ and $\mu(t)$ are assumed to not vary with age such that $\lambda(t)=\lambda$ and $\mu(t)=\mu$, then the link function for age-specific apparent prevalence is

$$
v_{c}(t)=\frac{1-e^{-(\lambda-\mu) t}}{1-\frac{\mu}{\lambda} e^{-(\lambda-\mu) t}}
$$

where the subscript $c$ indicates that the hazard functions are constant across age. Eq.1 specifies the age-specific prevalence while adjusting for the potentially higher mortality rate of disease-positive animals. Note that the disease-negative mortality hazard $\delta(t)$ has no influence on $v_{c}(t)$ (Cohen 1972, Heisey et al. 2006).

The assumption that the infection hazard is invariant with respect to age is often unrealistic. However, relaxation of this assumption generally requires specification of a functional form for the age-specific infection hazard. Following the lead of Heisey et al. (2006), we specify the following models.

$$
\begin{aligned}
& \text { Weibull: } \quad \lambda(t)=\alpha \beta(\alpha t)^{\beta-1} \\
& \text { Pareto: } \quad \lambda(t)=\frac{\alpha \beta}{1+\beta t} \\
& \text { Gompertz: } \quad \lambda(t)=e^{\alpha+\beta t} \\
& \text { Log-logistic: } \quad \lambda(t)=\frac{\alpha \beta(\alpha t)^{\beta-1}}{\left[1+(\alpha t)^{\beta}\right]}
\end{aligned}
$$

where for all models $\alpha$ and $\beta$ are scale and shape parameters, respectively, that control age dependency. Note that the Pareto is technically not an "age-varying" infection hazard model, but it is included with this group because its assumption of heterogeneous hazard offers flexibility to the baseline hazard function. Unlike the first three models, the log-logistic model allows the hazard to achieve a peak (i.e., it is not monotonic).

Investigation of the influence of covariates on the infection hazard is accomplished in the following manner:

$$
\lambda(t)=\lambda_{0}(t) e^{\mathbf{X} \beta}
$$

Here $\lambda_{0}$ is the baseline force-of-infection, $\mathbf{X}$ is the design matrix, and $\boldsymbol{\beta}$ is the vector of parameters associated with the covariates. The unit hazards ratio $e^{\boldsymbol{\beta}}$ measures how much of a unit change the $i$ th covariate, modeled as $e^{\mathbf{X} \boldsymbol{\beta}}$, shifts $\lambda(t)$ up or down (Collett 2003, Heisey et al. 2006). In the case of age-invariant infection hazard, $\lambda$ is not dependent on $t$, and Eq. 6 simplifies to $\lambda=\lambda_{0} e^{\mathbf{X} \boldsymbol{\beta}}$.

Application of the above age-variant hazard models within the three-state irreversible disease model framework does not allow for a closed-form solution of $\mathrm{v}(t)$. To overcome this difficulty, we use a recently developed piecewise approximation method that facilitates computation of $v(t)$ for any age-varying hazard function. Details of this method are given in Heisey et al. (2006).

The confidence intervals around $\beta_{i}$ and $\mu$ were generated by a profile likelihood approach. Models were refitted using fixed individual parameters $\theta$ surrounding the original estimated parameter $\hat{\theta}$. The 95\% confidence interval around $\hat{\theta}$ was defined as the set of $\theta$ for which the likelihood ratio statistic $G^{2}=2\left(L_{\hat{\theta}}-\right.$ $L_{\theta}$ ) was $<3.84\left(\chi_{0.05,1}^{2}\right)$ (Venzon and Moolgavkar 1988, Heisey et al. 2006).

Application to striped bass.-We fitted eight model structures with varying parameterizations for each specified force-of-infection, either $\lambda$ or $\lambda(t)$ depending on the assumptions of age dependency. All models were fitted using the $\mathrm{R}$ function ( $\mathrm{R}$ Development Core Team 2005) given in the supplement of Heisey et al. (2006). Age-1 through Age-10 fish were treated as individual age classes, while Age-11+ fish were binned. Four hundred 


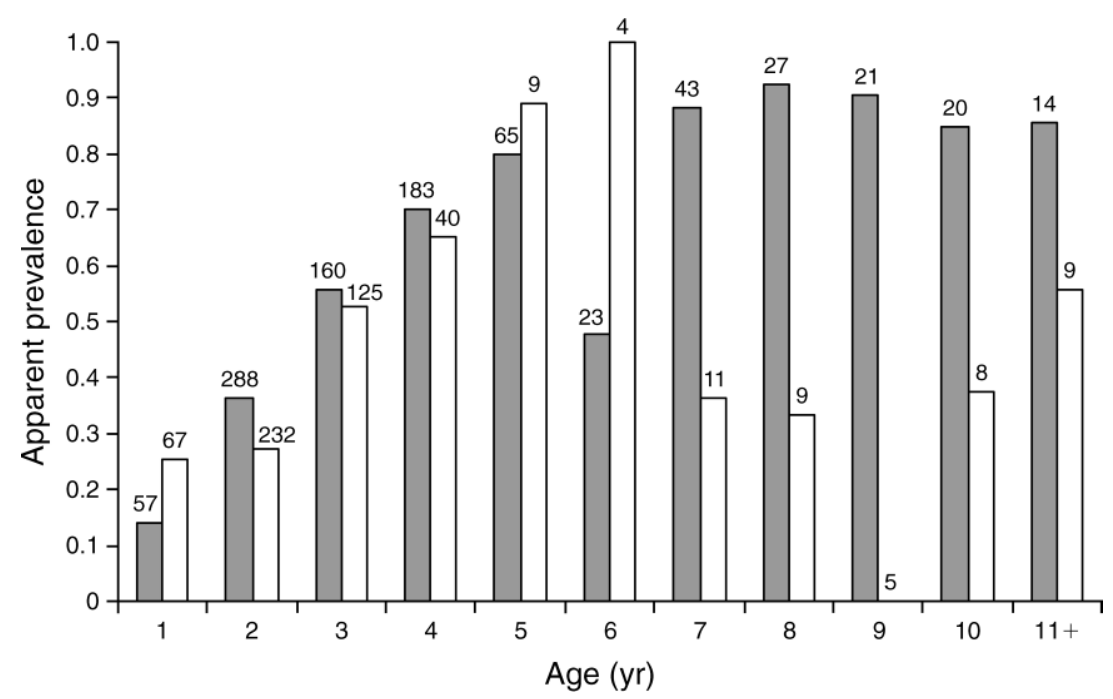

FIG. 3. Age-specific apparent mycobacteriosis prevalence for male (gray bars) and female (open bars) striped bass collected by the ChesMMAP survey during 2003-2005. Sample size is shown above each bar.

intervals were used to estimate $v(t)$ with piecewise methods (Heisey et al. 2006). Age-invariant hazard models included parameterization with or without the mortality term $\mu$ and age, sex, cruise (season), and/or year as covariates. The null model included only parameter(s) associated with the form of $\lambda$. Models including age as a covariate were intended to examine age dependency of force-of-infection. These models allowed $\ln \lambda$ to vary linearly $\left(\beta_{0}+\beta_{1} t\right)$ or quadratically $\left(\beta_{0}+\beta_{1} t^{2}\right)$ with age. Since $v_{c}(t)$ already incorporated age, including age as a covariate led to a model that did not correspond to a solution of the differential equations from the three-compartment model and thus did not have a hazards-based interpretation. However, inclusion of age as a covariate gave the model some flexibility and allowed examination of the assumption of age invariance of $\lambda$. If the inclusion of age as a covariate significantly improved model fit, then it was likely that assumption of age invariance of the infection hazard was incorrect and models other than $v_{c}(t)$ needed to be considered (Heisey et al. 2006). The final age-invariant hazard model included year as a covariate in order to examine the possibility that apparent prevalence varied annually.

Models incorporating age-variant force-of-infection functions were fitted according to the piecewise approximation method of Heisey et al. (2006). A total of 32 models including combinations of covariates sex and cruise and the mortality parameter $\mu$ were fitted. Individual hazard ratios were calculated for cruises 25 , with cruise 1 set as the reference level, and for sex, with males as the reference category. All model fits were assessed with Akaike's Information Criterion (AIC; Burnham and Anderson 2002). Likelihood ratio testing was used to examine differences between parameteriza- tions including $\mu$ and corresponding nested parameterizations not including $\mu$ (Woodward 2005).

\section{RESULTS}

\section{Apparent prevalence}

The analyses presented here include 1420 striped bass collected during the 2003-2005 sampling years. Of these, 519 were female and 901 were male. Ages 1-16 were represented in the sample, with the majority of fish between Ages 1 and 4 ( $n=1152$ fish).

Apparent prevalence increased by age category through Age 5 for both male and female fish, reaching $80.0 \%$ and $88.9 \%$, respectively (Fig. 3). Prevalence in Age- 6 males and females was $47.8 \%$ and $100 \%$, respectively, although the latter value is based on a sample size of four fish. Apparent prevalence was $>85 \%$ for Age-7+ males, whereas a marked reduction in apparent prevalence was observed in Age-7+ females.

Age-invariant $\lambda$ models. - The linear age covariate model did not demonstrate appreciably improved fit to the observed data relative to the constant $\lambda$ model without age covariate. Fit was markedly improved, however, in all parameterizations of the quadratic age covariate model (Table 1). The improved fit of the quadratic age covariate model indicated that assumption of age invariance of $\lambda$ within $v_{c}(t)$ was incorrect, and incorporation of hazard functions describing age variance of $\lambda$ was warranted. Treatment of year as a covariate did not improve fit significantly for any parameterization. This indicated that prevalence did not vary on an annual basis over the period of the study, and inclusion of year as a model covariate was contraindicated.

Age-variant models: $\lambda(t)$.- Among age-variant forceof-infection models, the log-logistic yielded consistently better model fits for all combinations of covariates and $\mu$ when compared to Weibull, Pareto, and Gompertz 
TABLE 1. Assessment of model fits based on Akaike's information criteria.

\begin{tabular}{|c|c|c|c|c|c|c|c|c|}
\hline \multirow[b]{2}{*}{ Models } & \multicolumn{8}{|c|}{$\Delta \mathrm{AIC}$} \\
\hline & Null & $\mu$ & Sex & Sex, $\mu$ & Cruise & Cruise, $\mu$ & Cruise, Sex & Cruise, Sex, $\mu$ \\
\hline \multicolumn{9}{|l|}{ Age-invariant $\lambda$} \\
\hline Constant $\lambda$ & 97.3 & 92.8 & 78.3 & 69.8 & 43.1 & 44.4 & 30.3 & 30.5 \\
\hline Linear age & 87.7 & 88.7 & 69.8 & 69.9 & 42.7 & 43.8 & 29.5 & 31.4 \\
\hline Quadratic age & 80.1 & 69.8 & 61.9 & 60.6 & 36.4 & 17.1 & 23.9 & 13.5 \\
\hline Year & 98.5 & 94.7 & 80.9 & 72.8 & 44.8 & 46.5 & 32.7 & 33.2 \\
\hline \multicolumn{9}{|l|}{ Age-variant $\lambda$} \\
\hline Weibull & 95.9 & 93.9 & 75.5 & 69.7 & 41.0 & 41.0 & 32.3 & 26.2 \\
\hline Gompertz & 88.6 & 90.6 & 68.8 & 70.1 & 42.9 & 44.8 & 29.7 & 31.7 \\
\hline Pareto & 90.6 & 92.2 & 70.6 & 70.7 & 43.5 & 45.5 & 30.3 & 32.0 \\
\hline Log-logistic & 83.3 & $73.0+$ & 65.0 & $56.2 \dagger$ & 26.3 & $7.6+$ & 15.5 & $0 \dagger$ \\
\hline
\end{tabular}

Notes: Age-invariant models use the link function $v_{c}(t)$. The null model includes only parameter(s) associated with the form of $\lambda$. Age is included as a covariate in "linear" $\left(\ln \lambda=\beta_{0}+\beta_{1} t\right)$ and "quadratic" $\left(\ln \lambda=\beta_{0}+\beta_{1} t^{2}\right)$ models. Year is included as a covariate in the "year" model. Age-variant force-of-infection models use different hazard functions to describe $\lambda(t)$ as defined in the text. Covariate parameterizations are in columns, and all fits for all models are calculated relative to the best-fit model (log-logistic, sex, cruise, $\mu)$. In all cases, significantly better fits were observed in models containing $\mu(P \leq 0.001)$. Where models have more than one parameter, they are not interactions.

$\dagger$ Models containing $\mu$ were compared to their respective restricted model in which $\mu=0$ with the likelihood ratio test.

hazard functions. The most fully parameterized loglogistic model, which included sex and cruise covariates as well as $\mu$, produced the lowest AIC value and was thus the reference model for comparisons. Inclusion of disease-associated mortality $\mu$ improved model fit significantly in all parameterizations of the log-logistic model (likelihood ratio test, $P \leq 0.001$ ). Inclusion of cruise alone as a covariate improved model fits considerably, whereas only modest decreases in $\triangle$ AIC were observed for models including sex alone (Table 1).

For the best-fitting model (log-logistic, sex, cruise, $\mu$ ), the unit hazard ratio for female relative to male fish was 0.78 (95\% CI: 0.68-0.88). Hazard ratios for cruises 2-5 relative to cruise 1 were $1.23(1.20-1.26), 1.29$ (1.26$1.32), 1.79(1.75-1.84)$, and $2.10(2.00-2.20)$, respectively (Fig. 4).

The disease-associated mortality term $\mu$ was estimated from the best-fitting model as 0.36 , with a $95 \%$ profile likelihood confidence interval of $0.18-0.59$. The annual survival ratio of a diseased animal relative to a nondiseased animal is calculated as $e^{-\mu}$ (Heisey et al. 2006). Relative to a non-diseased fish, the survival probability of a diseased fish from age $t$ to $t+1$ was therefore estimated as $0.69(0.55-0.84)$. From the analysis performed above, it appeared that inclusion of diseasespecific mortality in force-of-infection models was well supported. The disparity between apparent prevalence values in older female vs. male fish, however, generated concern that decreased prevalence in the former may be disproportionately driving estimations of $\mu$. In order to more directly examine the relative contributions of sexspecific apparent prevalence patterns to the estimate of $\mu$, an additional analysis was performed under log-logistic infection hazard and cruise covariate with data stratified by sex. For male striped bass, $e^{-\mu}$ was estimated as 0.79 (0.57-1.01), and the $\triangle \mathrm{AIC}$ value for $\mu$-containing vs. non- $\mu$-containing models decreased to 1.62 . Likelihood ratio testing gave marginal support for $\mu$ models vs. non- $\mu$ models $(P=0.057)$. For female fish, estimated $e^{-\mu}$ was $0.49(0.22-0.76)$. $\Delta$ AIC between $\mu$-containing and non- $\mu$ containing models was 11.9 , and likelihood ratio testing indicated significant improvement of model fit for the $\mu$ containing model $(P<0.001)$.

\section{Discussion}

Apparent prevalence of mycobacteriosis in male fish increased with age, reaching its highest levels in Age-7+ fish. Apparent prevalence in female fish was similar to that in males through Age 5; however, prevalence declined considerably in older female fish. Striped bass are sexually dimorphic with respect to growth dynamics and migratory behavior. The rate at which female fish approach their maximum size, as well as maximum size attained, are greater than those of males (Murdy et al. 1997, McNamee 2007). It is generally thought that female fish begin migration outside Chesapeake Bay at an earlier age than males. The degree to which this occurs, however, is unclear (Kohlenstein 1981, Dorazio et al. 1994), and recent otolith microchemistry analyses have indicated that large numbers of both female and male fish may remain resident in Chesapeake Bay throughout their lives (Secor and Piccoli 2007). The reason for the marked difference in prevalence between older male and female fish may lie in differing migratory patterns, spawning stresses, or other life history differences. Better information about the life history of striped bass, as well as risk factors for development of mycobacteriosis, will be necessary to explore these hypotheses.

The three-compartment irreversible disease model used in this study makes the explicit assumption that reversion to a non-diseased state does not occur (i.e., once a fish is diseased it will remain detectably diseased). Therefore, the decline in prevalence observed in older female fish is expressed by this model as diseaseassociated mortality. Similar assumptions of disease 

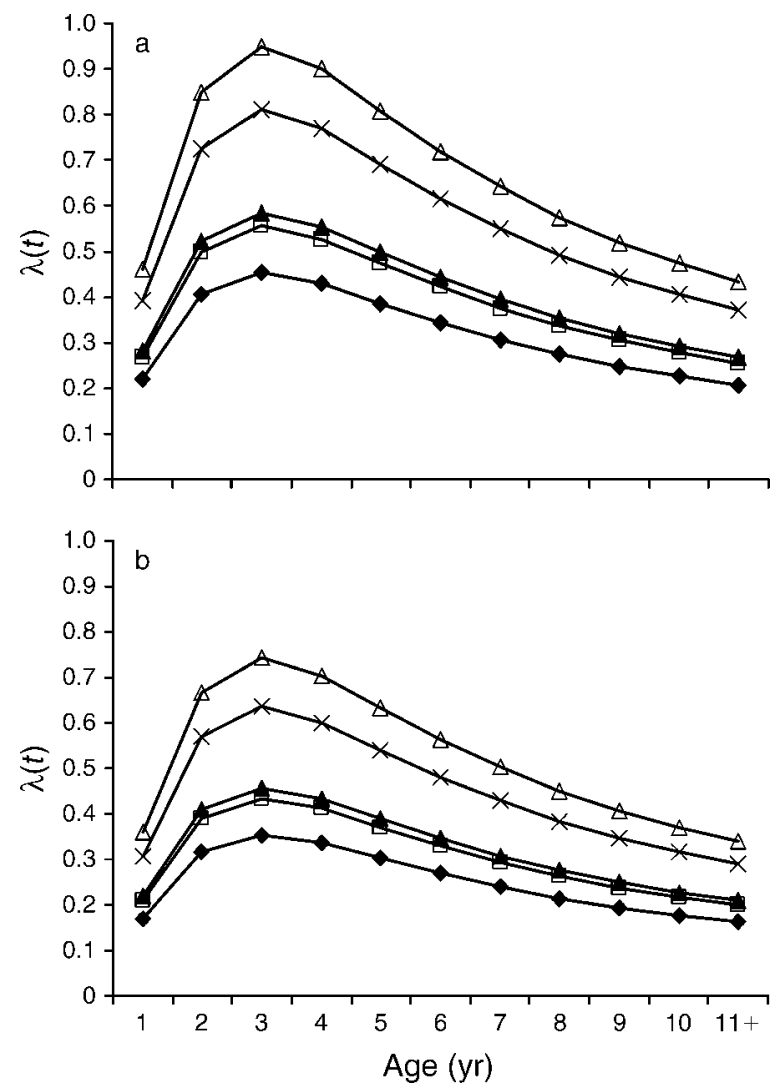

FIG. 4. Force-of-infection, $\lambda(t)$, calculated from the best-fit model (log-logistic, sex, cruise, $\mu$ ) for (a) male and (b) female striped bass. Cruises: 1 (solid diamond), 2 (open square), 3 (solid triangle), 4 (X), and 5 (open triangle) represent March, May, July, September, and November, respectively, from 2003 to 2005 .

irreversibility have been made explicitly or implicitly in previous studies of mycobacteriosis in wildlife (Anderson and Trewhella 1985, Caley and Hone 2002, Heisey et al. 2006), and it is generally assumed that mycobacteriosis in fishes is chronic, progressive, and ultimately fatal (Van Duijn 1981, Frerichs 1993, Decostere et al. 2004). Regression or resolution of mycobacteriosis in naturally or experimentally infected fishes has not, to our knowledge, been described. Long-term (45 weeks) experimentally induced mycobacterial infections in striped bass resulted in progressive granuloma formation and, in $M$. marinum infections, secondary recrudescent disease (Gauthier et al. 2003). Death of diseased female wild striped bass in Chesapeake Bay, perhaps due to energetic demands of spawning and migration, is therefore plausible and not contraindicated by available data. The ability of mycobacteria of human and veterinary importance to enter latency, however, is well known (Flynn and Chan 2001), and the possibility that fishes (striped bass in particular) may in some circumstances resolve mycobacterial granulomas remains an important consideration to the model used in this study.
Simple models of disease dynamics often assume that force-of-infection is constant through time. This assumption, however, is seldom realistic in natural systems, as force-of-infection can vary considerably with several factors, including host/pathogen density and life history traits (Scott and Smith 1994). The assumption of age-invariant $\lambda$ in modeling these data was tested with "diagnostic" models incorporating age as a covariate (Heisey et al. 2006). The improved fit of these models suggested age dependency of $\lambda(t)$, and indicated the use of more complex hazard functions describing force-of-infection in the context of $v(t)$. It is worth noting that we assumed age-invariant diseaseassociated mortality $(\mu)$. Age-variant disease-associated mortality could have significant implications for this model, and future efforts will explore this possibility.

Model parameterizations including year as a covariate were applied assuming age-invariant $\lambda$ in order to test possible effects of annual variation in disease prevalence. The apparent constancy of annual prevalence demonstrated by these parameterizations indicates that annual prevalence of mycobacteriosis in Chesapeake Bay striped bass was stable from 2003 to 2005. Diseases with low pathogenicity and long persistence times generally tend toward endemicity (Anderson and May 1979), and it may be that striped bass mycobacteriosis would best be described as an endemic, rather than epidemic disease. An additional consideration is the recent, large fluctuation in striped bass population size. Striped bass populations along the eastern seaboard of the United States experienced a collapse in the late 1970s and 1980s, followed by a robust recovery thought to be due primarily to fishing moratoria and favorable environmental conditions leading to strong recruitment (Field 1997, Richards and Rago 1999). The level of disease prevalence currently observed may be related in part to increased host density, and may therefore have a different "stable" level when striped bass populations are lower. Unfortunately, comparable historical information about bay-wide disease prevalence is not available, so meaningful inferences about long-term disease trends are not possible. Accommodation of calendar time as well as age influences in the force-ofinfection models used in this work is theoretically feasible, but will require long-term data sets to avoid confounding effects (Heisey et al. 2006).

Age-variant models using the log-logistic hazard function demonstrated markedly improved fit over models using Weibull, Gompertz, or Pareto hazard functions. The improved fit of the log-logistic model is perhaps not surprising, as the freedom of the log-logistic hazard function to peak lends it flexibility not found in monotonic models (Collett 2003). Lower initial force-ofinfection values may reflect a lag period between infection and disease expression in younger fish. Interpretation of the post-modal decline in force-ofinfection with increasing age is dependent in large part on the mechanism(s) of mycobacterial transmission to 
striped bass. Transmission of mycobacteriosis in fishes is poorly understood, although ingestion appears to be an important route (Ross and Johnson 1962, Ross 1970, Hariff et al. 2007). Transovarian transmission has been reported for livebearing fishes (Conroy 1966). The degree to which mycobacteria are transmitted to wild fishes from environmental matrices, as well as the occurrence of fish-to-fish transmission in natural habitats are unknown. The latter process would almost certainly incur density dependency of force-of-infection, and declining force-of-infection with age could readily be attributed to lower densities of susceptible (negative) hosts. Potential relationships between declining agespecific force-of-infection and mechanisms of indirect waterborne transmission are less straightforward, and development of relevant hypotheses will require a better understanding of the host-pathogen ecology of this disease.

Based on $\triangle \mathrm{AIC}$ estimation of model fit, both cruise and sex covariates were found to influence infection hazard in the log-logistic model (Fig. 4). Female fish were found to have a lower infection hazard than male fish, and hazard by cruise increased as the year progressed. Sex-specific differences in force-of-infection are likely related to life history differences (e.g., migration), and may also be due to physiological differences such as spawning stress. Seasonality of hazard may be due to environmental stressors, such as increased summer temperatures and seasonal hypoxia found in Chesapeake Bay (Kemp et al. 2005). Region was not included as a covariate in these analyses, as the highly migratory nature of striped bass would make interpretation of regional effects on the model difficult.

Both $\triangle \mathrm{AIC}$ model comparisons and likelihood ratio testing supported the inclusion of disease-associated mortality $\mu$ as a model parameter. Additionally, the $95 \%$ confidence interval around the estimated value of disease-associated mortality $e^{-\mu}$ did not include unity. Taken together, these analyses indicated that, under the assumptions of this modeling approach, significant disease-associated mortality occurred in Chesapeake Bay striped bass. The manner or degree in which mycobacteriosis may be regulating the striped bass population, however, remains unknown. Development of predictive dynamic models of disease effects on the striped bass population is beyond the scope of this work; however it is our hope that the model presented here will lay the foundations for future efforts of this type.

Bias toward overestimation or underestimation of prevalence can be expected to have specific effects on the models described in this study. Prevalence underestimation would be expected to mimic disease-associated mortality, leading to inflated estimates of $\mu$ and improved model fits for parameterizations including $\mu$. Conversely, overestimation of prevalence would be expected to produce underestimates of $\mu$. Disease status in this study was determined based on histologic detection of splenic granulomas. This approach has also been used in previous studies of mycobacteriosis in striped bass (e.g., Overton et al. 2003); however its specificity is imperfect due to the occasional presence of other granuloma-eliciting agents. Acid-fast staining may be used to positively identify mycobacteria in tissue sections; however, acid-fast bacilli (AFB) are not always visible in mycobacterial granulomas of fishes (Daoust et al. 1989, Colorni et al. 1998, Gauthier et al. 2003), and classifying disease status by presence of AFB is therefore likely to underestimate prevalence. By erring on the side of prevalence overestimation, we have therefore taken a conservative approach toward estimation of $\mu$. Sampling may represent another source of prevalence bias in this study, as it is possible that disease status may influence relative capture probability of fish by the ChesMMAP trawl gear. As mycobacteriosis generally results in debilitation of affected fishes, it seems plausible that the direction of bias in this case would be towards collection of diseased individuals. This would again be expected to make the analysis more conservative with respect to estimation of $\mu$; however we acknowledge that effects of disease on relative distribution and catchability of striped bass are unknown.

Disease-associated mortality was demonstrated at the level of the entire data set, which included both male and female fish. Visual inspection of the apparent prevalence data, however, gives the impression that sex-specific disease processes may be present. Moreover, the depression of apparent prevalence in older female fish begs the question of whether this group may be disproportionately driving the model-estimated mortality. Refitting the full log-logistic model to male fish alone narrowly failed to reject the null hypothesis of no mortality (likelihood ratio test, $P=0.057$ ). Sensitivity analysis, however, indicated that recategorizing $5 \%$ of disease-positive male fish to disease negative was sufficient to reject the null hypothesis and support the model in which $\mu \neq 0$. These results may best be interpreted as indicating that disease-associated mortality in male fish, if it occurs, is modest.

The striped bass is an economically and ecologically important finfish along the eastern seaboard of the United States. As such, high prevalence of a potentially lethal infectious disease in this species is of considerable concern to fisheries managers and user groups. In this work, we provide the first evidence for mycobacteriosisassociated mortality in striped bass of Chesapeake Bay, the dominant breeding and nursery ground for the striped bass along the Atlantic coast. This evidence is based on a novel modeling approach to estimating forceof-infection from age-prevalence data (Heisey et al. 2006). The method we describe here depends on several assumptions, including irreversibility of disease and ageinvariant disease-associated mortality. These assumptions are reasonable given the current understanding of mycobacterial pathobiology in fishes, but require testing, especially in the context of wild populations. We intend this work to drive formulation of hypotheses 
to test these assumptions, and thus to aid in development of more sophisticated models of disease dynamics based on directed field and experimental data.

\section{ACKNOWLEDGMENTS}

The authors acknowledge E. A. Brasseur, P. D. Lynch, D. J. Parthree, R. A. Johnson, and M. L. F. Chattin for their efforts associated with field collections. L. Durand Ward and the Virginia Institute of Marine Science vessels staff deserve thanks for their contributions to the field component of this study. Ashley Haines provided critical review and comments on this manuscript. Funding was provided by the National Oceanic and Atmospheric Administration Chesapeake Bay Office, Virginia Environmental Endowment, Virginia Marine Resources Commission Recreational Fishery Advisory Board, and the U.S. Fish and Wildlife Service. This is VIMS contribution \#2914.

\section{Literature Cited}

Anderson, R. M., and R. M. May. 1979. Population biology of infectious diseases: Part I. Nature 280:361-366.

Anderson, R. M., and W. Trewhella. 1985. Population dynamics of the badger (Meles meles) and the epidemiology of bovine tuberculosis (Mycobacterium bovis). Philosophical Transactions of the Royal Society of London, B Biological Sciences 310:327-381.

Baya, A. M., B. Lupiani, F. M. Hetrick, B. S. Roberson, R. Lukacovic, E. May, and C. Poukish. 1990. Association of Streptococcus sp. with fish mortalities in the Chesapeake Bay and its tributaries. Journal of Fish Diseases 13:251-253.

Baya, A. M., J. L. Romalde, D. E. Green, R. B. Navarro, J. Evans, E. B. May, and A. E. Toranzo. 1997. Edwardsiellosis in wild striped bass from the Chesapeake Bay. Journal of Wildlife Diseases 33:517-525.

Blazer, V. S., J. H. Lilley, W. B. Schill, Y. Kiryu, C. L. Densmore, V. Panyawachira, and S. Chinabut. 2002. Aphanomyces invadans in Atlantic menhaden along the east coast of the United States. Journal of Aquatic Animal Health 14:1-10.

Bruno, D. W., J. Griffiths, C. G. Mitchell, B. P. Wood, Z. J. Fletcher, F. A. Drobniewski, and T. S. Hastings. 1998. Pathology attributed to Mycobacterium chelonae infection among farmed and laboratory-infected Atlantic salmon Salmo salar. Diseases of Aquatic Organisms 33:101-109.

Burnham, K. P., and D. R. Anderson. 2002. Model selection and inference: a practical information-theoretic approach. Second edition. Springer-Verlag, New York, New York, USA.

Caley, P., and J. Hone. 2002. Estimating the force of infection; Mycobacterium bovis infection in feral ferrets Mustela furo in New Zealand. Journal of Animal Ecology 71:44-54.

Cardinal, J. L. 2001. Mycobacteriosis in striped bass, Morone saxatilis, from Virginia waters of Chesapeake Bay. Thesis. College of William and Mary, Virginia Institute of Marine Science, Gloucester Point, VA.

Cohen, J. E. 1972. When does a leaky compartment model appear to have no leaks? Theoretical Population Biology 3: 404-405.

Cohen, J. E. 1973. Selective host mortality in a catalytic model applied to schistosomiasis. American Naturalist 107:199-212.

Collett, D. 2003. Modelling survival data in medical research. Second edition. Chapman and Hall, London, UK.

Colorni, A., R. Avtalion, W. Knibb, E. Berger, B. Colorni, and B. Timan. 1998. Histopathology of sea bass (Dicentrarchus labrax) experimentally infected with Mycobacterium marinum and treated with streptomycin and garlic (Allium sativum) extract. Aquaculture 160:1-17.

Conroy, D. 1966. A report on the problems of bacterial fish diseases in the Argentine Republic. Bulletin Office International des Epizooties 65:755-768.
Cotran, R. S., V. Kumar, and T. Collins. 1999. Pathologic basis of disease. Sixth edition. W. B. Saunders, Philadelphia, Pennsylvania, USA.

Daoust, P.-Y., B. E. Larson, and G. R. Johnson. 1989. Mycobacteriosis in yellow perch (Perca flavescens) from two lakes in Alberta. Journal of Wildlife Diseases 25:31-37.

Decostere, A., K. Hermans, and F. Haesebrouck. 2004. Piscine mycobacteriosis: a literature review covering the agent and the disease it causes in fish and humans. Veterinary Microbiology 99:159-166.

Dorazio, R. M., K. A. Hattala, C. B. McCollough, and J. E. Skjeveland. 1994. Tag recovery estimates of migration of striped bass from spawning areas of the Chesapeake Bay. Transactions of the American Fisheries Society 123:950-963.

Field, J. D. 1997. Atlantic striped bass management: Where did we go right? Fisheries 22:6-8.

Flynn, J. L., and J. Chan. 2001. Tuberculosis: latency and reactivation. Infection and Immunity 69:4195-4201.

Frerichs, G. N. 1993. Mycobacteriosis: nocardiosis. Pages 219235 in V. Inglis, R. J. Roberts, and N. R. Bromage, editors. Bacterial diseases of fish. Blackwell Scientific, London, UK.

Gauthier, D. T., M. W. Rhodes, W. K. Vogelbein, H. Kator, and C. A. Ottinger. 2003. Experimental mycobacteriosis in striped bass (Morone saxatilis). Diseases of Aquatic Organisms 54:105-117.

Hariff, M. J., L. E. Bermudez, and M. L. Kent. 2007. Experimental exposure of zebrafish, Danio rerio (Hamilton) to Mycobacterium marinum and Mycobacterium peregrinum reveals the gastrointestinal tract as the primary route of infection: a potential model for environmental mycobacterial infection. Journal of Fish Diseases 30:587-600.

Hartman, K. J., and S. B. Brandt. 1995. Trophic partitioning, diets, and growth of sympatric estuarine predators. Transactions of the American Fisheries Society 124:520-537.

Hedrick, R. P., T. McDowell, and J. Groff. 1987. Mycobacteriosis in cultured striped bass from California. Journal of Wildlife Diseases 23:391-395.

Heisey, D. M., D. O. Joly, and F. Messier. 2006. The fitting of general force-of-infection models to wildlife disease prevalence data. Ecology 87:2356-2365.

Herbst, L. H., S. F. Costa, L. M. Weiss, L. K. Johnson, J. Bartell, R. Davis, M. Walsh, and M. Levi. 2001. Granulomatous skin lesions in moray eels caused by a novel mycobacterium species related to Mycobacterium triplex. Infection and Immunity 69:4639-4646.

Jiang, H., J. M. Pollock, C. Brownie, J. M. Hoenig, R. J. Latour, B. K. Wells, and J. E. Hightower. 2007. Tag return models allowing for harvest and catch and release: evidence of environmental and management impacts on striped bass fishing and natural mortality rates. North American Journal of Fisheries Management 27:387-396.

Keiding, N. 1991. Age-specific incidence and prevalence: a statistical perspective. Journal of the Royal Statistical Society, Series A 154:371-412.

Kemp, W. M., et al. 2005. Eutrophication of Chesapeake Bay: historical trends and ecological interactions. Marine Ecology Progress Series 303:1-29.

Kent, M. L., C. M. Whipps, J. L. Matthews, D. Florio, V. Watral, J. K. Bishop-Stewart, M. Poort, and L. Bermudez. 2004. Mycobacteriosis in zebrafish (Danio rerio) research facilities. Comparative Biochemistry and Physiology, C 138: 383-390.

Kirkley, J. E., K. E. McConnell, and W. Ryan. 2000. Economic aspects of allocating striped bass among competing user groups in Virginia. Virginia Marine Resources Report, No. 2000-05, Newport News, Virginia, USA.

Kohlenstein, L. C. 1981. On the proportion of the Chesapeake Bay stock of striped bass that migrates into the coastal fishery. Transactions of the American Fisheries Society 110: $168-179$. 
Lansdell, W., B. Dixon, N. Smith, and L. Benjamin. 1993. Isolation of several Mycobacterium species from fish. Journal of Aquatic Animal Health 5:73-76.

Latour, R. J., J. Gartland, C. F. Bonzek, and R. A. Johnson. 2008. The trophic dynamics of summer flounder (Paralichthys dentatus) in Chesapeake Bay. Fishery Bulletin 106:4757.

McNamee, K. 2007. Trophic ecology and growth dynamics of striped bass (Morone saxatilis) in Chesapeake Bay, with reference to mycobacteriosis. Thesis. Virginia Institute of Marine Science, Gloucester Point, Virginia, USA.

Murdy, E. O., R. S. Birdsong, and J. A. Musick. 1997. Fishes of Chesapeake Bay. Smithsonian Institution Press, Washington, D.C., USA.

Nigrelli, R. F., and H. Vogel. 1963. Spontaneous tuberculosis in fishes and in other cold-blooded vertebrates with special reference to Mycobacterium fortuitum Cruz from fish and human lesions. Zoologica: New York Zoological Society 48: 131-144.

Overton, A. S., F. J. Margraf, C. A. Weedon, L. H. Pieper, and E. B. May. 2003. The prevalence of mycobacterial infections in striped bass in Chesapeake Bay. Fisheries Management and Ecology 10:301-308.

Patterson, K. R. 1996. Modelling the impact of disease-induced mortality in an exploited population: the outbreak of the fungal parasite Ichthyophonus hoferi in the North Sea herring (Clupea harengus). Canadian Journal of Fisheries and Aquatic Science 53:2870-2887.

Podgor, M. J., and M. C. Leske. 1986. Estimating incidence from age-specific prevalence for irreversible diseases with differential mortality. Statistics in Medicine 5:573-578.

Prophet, E. B., B. Mills, J. B. Arrington, and L. H. Sobin. 1992. Laboratory methods in histotechnology. Armed Forces Institute of Pathology. American Registry of Pathology, Washington, D.C., USA.

R Development Core Team. 2005. R: a language and environment for statistical computing. R Foundation for Statistical Computing, Vienna, Austria.

Ranger, B. S., E. A. Mahrous, L. Mosi, S. Adusumilli, R. E. Lee, A. Colorni, M. Rhodes, and P. L. C. Small. 2006. Globally distributed mycobacterial fish pathogens produce a novel plasmid-encoded toxic macrolide, mycolactone $\mathrm{F}$. Infection and Immunity 74:6037-6045.

Rhodes, M. W., H. Kator, I. Kaattari, D. Gauthier, W. Vogelbein, and C. A. Ottinger. 2004. Isolation and characterization of mycobacteria from striped bass Morone saxatilis from the Chesapeake Bay. Diseases of Aquatic Organisms 61: 41-51.

Rhodes, M. W., H. Kator, S. Kotob, P. van Berkum, I. Kaattari, W. Vogelbein, M. M. Floyd, W. R. Butler, F. D. Quinn, C. Ottinger, and E. Shotts. 2001. A unique Mycobacterium species isolated from an epizootic of striped bass (Morone saxatilis). Emerging Infectious Diseases 7:896899.

Rhodes, M. W., H. Kator, S. Kotob, P. van Berkum, I. Kaattari, W. K. Vogelbein, F. Quinn, M. M. Floyd, W. R. Butler, and C. A. Ottinger. 2003. Mycobacterium shottsii sp. nov., a slowly growing species isolated from Chesapeake Bay striped bass. International Journal of Systematic and Evolutionary Microbiology 53:421-424.

Rhodes, M. W., et al. 2005. Mycobacterium pseudoshottsii sp. nov., a slowly growing chromogenic species isolated from Chesapeake Bay striped bass (Morone saxatilis). International Journal of Systematic and Evolutionary Microbiology 55: $1139-1147$.

Richards, R. A., and P. J. Rago. 1999. A case history of effective fishery management: Chesapeake Bay striped bass.
North American Journal of Fisheries Management 19:356375.

Ross, A. J. 1970. Mycobacteriosis among Pacific salmonid fishes. Pages 279-283 in S. F. Snieszko, editor. A symposium on diseases of fishes and shellfishes. American Fisheries Society, Special publication 5, Washington, D.C., USA.

Ross, A. J., and H. E. Johnson. 1962. Studies of transmission of mycobacterial infections in Chinook salmon. The Progressive Fish-Culturist 24:147-149.

Sakanari, J. A., C. A. Reilly, and M. Moser. 1983. Tubercular lesions in Pacific coast populations of striped bass. Transactions of the American Fisheries Society 112:565-566.

Scott, M. E., and G. Smith. 1994. Parasitic and infectious diseases: epidemiology and ecology. Academic Press, San Diego, California, USA.

Secor, D. H., and P. M. Piccoli. 2007. Oceanic migration rates of Upper Chesapeake Bay striped bass (Morone saxatilis), determined by otolith microchemical analysis. Fisheries Bulletin 105:62-73.

Secor, D. H., M. T. Trice, and H. T. Hornick. 1995. Validation of otolith-based ageing and a comparison of otolith- and scale-based ageing in mark-recaptured Chesapeake Bay striped bass Morone saxatilis. Fishery Bulletin 93:186-190.

Snieszko, S. F. 1978. Mycobacteriosis (tuberculosis) of fishes. U.S. Fish and Wildlife Service. Fish disease leaflet 55:1-9.

Tortoli, E., A. Bartoloni, E. Bozzetta, C. Burrini, C. Lacchini, A. Mantella, V. Penati, M. V. Simonetti, and C. Ghittino. 1996. Identification of the newly described Mycobacterium poriferae from tuberculous lesions of the snakehead fish (Channa striatus). Comparative Immunology, Microbiology and Infectious Diseases 19:25-29.

Van Duijn, C. 1981. Tuberculosis in fishes. Journal of Small Animal Practice 22:391-401.

Venzon, D. J., and S. H. Moolgavkar. 1988. A method for computing profile-likelihood-based confidence intervals. Applied Statistics 37:87-94.

Vogelbein, W. K., D. E. Zwerner, H. Kator, M. W. Rhodes, and J. Cardinal. 1999. Mycobacteriosis of striped bass from Chesapeake Bay. VIMS Special Scientific Report 139, Virginia Institute of Marine Science, Gloucester Point, Virginia, USA.

Whipps, C. M., V. G. Watral, and M. L. Kent. 2003. Characterization of a Mycobacterium sp. in rockfish, Sebastes alutus (Gilbert) and Sebastes reedi (Westrheim \& Tsuyuki), using rDNA sequences. Journal of Fish Diseases 26:241-245.

Whittington, R. J., J. B. Jones, P. M. Hine, and A. D. Hyatt. 1997. Epizootic mortality in the pilchard Sardinops sagax neopilchardus in Australia and New Zealand in 1995. I. Pathology and epizootiology. Diseases of Aquatic Organisms 28:1-16.

Wolke, R. E., and R. K. Stroud. 1978. Piscine mycobacteriosis. Pages 269-275 in R. J. Montali, editor. Symposium on mycobacterial infections of zoo animals. Smithsonian Institution, Front Royal, Virginia, USA.

Woodward, M. 2005. Epidemiology: study design and data analysis. Second edition. Chapman and Hall/CRC, Boca Raton, Florida, USA.

Woolhouse, M. E. J., and S. K. Chandiwana. 1992. A further model for temporal patterns in the epidemiology of schistosome infections of snails. Parasitology 104:443-449.

Yip, M. J., J. L. Porter, J. A. M. Fyfe, C. J. Lavender, F. Portaels, M. W. Rhodes, H. Kator, A. Colorni, G. A. Jenkin, and T. Stinear. 2007. Evolution of Mycobacterium ulcerans and other mycolactone-producing mycobacteria from a common Mycobacterium marinum progenitor. Journal of Bacteriology 189:2021-2029. 